\title{
Practice of CBL Teaching Method in Java Programming Teaching Based on Network Teaching Platform
}

\author{
Hu Xiangliang ${ }^{1, ~ a, ~ W a n g ~ G e n s h e n g ~}{ }^{1, b}$, Huang Xuejian ${ }^{1, c}$, Wu Xiaofang 1, d \\ ${ }^{1}$ Computer Practice Teaching Center, Jiangxi University of Finance and Economics, China

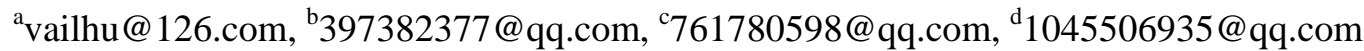

Keywords: Network teaching; J2EE; Case teaching

\begin{abstract}
The problems existing in the current JAVA teaching are analyzed, and the CBL teaching method based on the network teaching platform is adopted. The teaching method is applied to the teaching of JAVA, which is beneficial to enhance the initiative of the classroom teaching, fully mobilize the enthusiasm of the students, improve the students' practical ability and innovation ability, and have achieved good teaching results.
\end{abstract}

\section{Introduction}

The concept of modern education requires the cultivation of students' interest in learning, the cultivation of students' ability and overall quality, and the establishment of the thinking mode of the students' project, and the improvement of the practical ability of the students[1]. Using the network teaching platform to carry out classroom teaching is a new teaching method. It is a kind of new teaching method, it is the traditional classroom teaching content requirements fixed in the platform, students can not be restricted by time and place, anywhere in the field to study, change the traditional teaching mode of instillation, but also can improve the initiative of students' autonomy[2][3].

Case-based learning (CBL) is a kind of interactive teaching method, which is first applied in medicine, law and other disciplines. Its advantage lies in close contact with reality. It can make the theoretical concept easier to understand through the training of case project. This makes the teaching activities closer to reality and thus avoids the empty sermon [4][5]. This paper mainly explores the application and experience of case teaching method in the teaching of JAVA programming course under the support of network teaching platform.

\section{The Present Situation of Java Programming Teaching}

At present, most colleges and universities have opened the Java program design course [6], the main goal is to learn the core content of the Java programming language quickly through the comprehensive and systematic learning of the Java programming language, and learn to use the language knowledge and object-oriented programming ideas flexibly. This course is usually set up for sophomores and juniors. There are mainly several problems.

First, it spends too much grammar class. In the initial stage of learning JAVA, students must spend a lot of time and energy, mainly because JAVA is a boring and complicated course. Students must learn the basic knowledge actively, but the proficiency of basic knowledge does not mean that the ability of language programming will be improved. At present, in the course of JAVA teaching, teachers pay too much attention to the imparting of grammar knowledge, but ignore the training of students' practical operation ability. They do not fully use the practice of classroom practice to train students' practical ability. This will not only affect the mastery of students' basic knowledge, but also impede the training of students' programming ability. Therefore, teachers should arrange classroom teaching time reasonably.

Second, students' enthusiasm and interest are insufficient. At present. JAVA teacher centered teaching mode has been unable to adapt to students' learning needs, and can not fully arouse students' 
learning enthusiasm and interest. In JAVA classroom teaching, some teachers have always used traditional teaching mode to make students very passive, and JAVA course is a course that requires students to give full play to their enthusiasm and initiative in order to master knowledge and ability. Therefore, teachers must take effective measures to cultivate students' interest and spirit of inquiry in order to improve their learning. Comprehensive ability.

Third, teachers' teaching methods are improper. In the process of teaching, the teaching plan is generally equal to theoretical and experimental classes, and the actual training time of students is seriously insufficient. There are still many teachers' teaching content in the experimental course, which only plays a role in verifying the knowledge of grammar, lacking coherence and systematicness. In this way, students can accomplish the specific tasks of teachers' arrangement and learn some knowledge, but they can not accumulate practical experience, which can not effectively improve their own practical ability.

The traditional teaching is based on the theoretical knowledge point of teacher teaching, the data structure and algorithm involved in the program are introduced to the students, and then the operation effect of the program code is given. The students stay in the level that is not done, but the students may have problems in the process of configuring the basic environment, which leads to the waste of the class time. But after class, the students are helpless to complete the complex experiment, and the course needs the students to master the knowledge and practical skills, which can not achieve good teaching effect.

\section{Design of CBL Teaching Mode Based on Network Teaching Platform}

With the development of modern educational technology, many colleges and universities have used network teaching platform to assist teaching. The network teaching platform takes the curriculum as the leading part, the teacher opens the network course on the platform and writes the case to the platform according to the needs. The students can choose the curriculum freely and study the course content independently according to the training plan. According to the needs of teaching, teachers and students can exchange and interact on the platform, and provide a powerful teaching and learning online virtual environment for teachers and students, which can greatly improve the students' enthusiasm for learning[7]. The design of CBL teaching mode based on network teaching platform is shown below, as shown in Fig. 1.

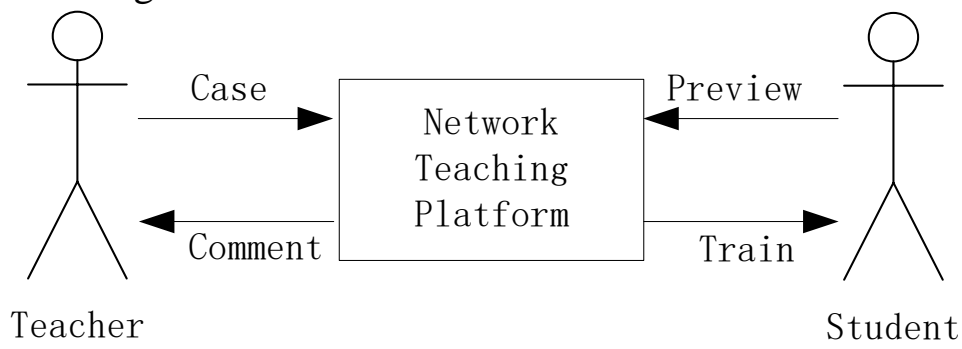

Fig. 1 CBL teaching model based on network teaching platform

First, teachers should select course cases carefully according to the requirements of the curriculum, and design and produce multimedia courseware for network courses in combination with the actual project and the knowledge points in the syllabus. Then the students preview the classroom teaching content on the network teaching platform before class, train the case with the content of the class, write the case code and submit it to the network teaching platform. Secondly, teachers need to review the code submitted by students and give comments. Finally, the team completed the team work as the final assessment, which can not only test the knowledge of the students, improve the practical ability of the students, but also cultivate the students' comprehensive thinking and teamwork ability. 


\section{Implementation of CBL Teaching Mode Based on Network Teaching Platform}

\subsection{Teaching Preparation}

According to the teaching arrangement, 182 students in three classes of this semester will be divided into several groups to manage the network teaching platform with 6 students in each group. The purpose is to fully mobilize the students' ability to think and consult the information actively and improve their learning efficiency.

\subsection{Teaching Implementation}

According to the requirements of teaching contents and experimental contents, teachers collect some deep, detailed, clear and case projects within the scope of students' abilities. Then the contents and cases to be explained are uploaded to the network teaching platform in the order of chapters in advance, and set up as "the mode of breaking through the customs", that is, the students must first complete the learning of relevant knowledge points before they can watch the related cases. After completing the learning of knowledge points and cases, students need to analyze and arrange cases and implement them autonomously, and finally make case reports to PPT. In this way, students can not only learn according to their requirements, but also exercise their initiative in autonomous learning.

The experimental class is mainly based on PPT report and actual case demonstration. Each member of the group should report on the basis of the actual completion. After that, the whole class will discuss and answer questions with the teachers. At the end, teachers evaluate the report and performance of the group, and further deepen the learning content and focus of the class, and correct some common mistakes and ideas. Next, take the teaching content of the last experimental course as an example to introduce the implementation process of teaching.

The last experimental class completed the design and development of a B/S system including front and back operations for each group. Inform students of the optional system project in advance. Each group chooses one project to design and develop the system, and then report and demonstrate the system. Teachers and team leaders are graded according to project introduction, system presentation, project defense and so on. This score accounted for $50 \%$ of the final student assessment, $30 \%$ of homework, and $20 \%$ of attendance and classroom performance.

\subsection{Teaching Effectiveness}

The teaching method is used in the 2016 grade software engineering undergraduate students of a university in Jiangxi. Through the statistics of the students' achievements in this class, there are 39 people (21.4\%) with a score above 90 points, 89 (48.9\%) from 80 to 90 points, 48 (26.4\%) with scores from 60 to 80, and only 6 below the 60 score. People (3.3\%). The results show that this method is helpful to improve students' grades in the teaching process.

At the same time, a total of 182 people in 3 classes were investigated by questionnaire[8], and 177 (97.3\%) welcomed the teaching method. It was believed that this teaching method was feasible and had significant effect on improving students' autonomous learning ability. Only 5 people (2.7\%) were not advisable to this teaching mode, thought the learning task was heavy, the spare time was compressed and blocked. It hinders its individualized development. The effect of the specific investigation is shown in Table 1.

In Table 1, the survey and statistics of the teaching effect: the majority of the students think that the JAVA program design based on the network teaching platform can improve the students' ability to learn, make the students more fully aware of the software development and project analysis, and have a certain hands-on ability for the research and development of the project. Improve the ability to think independently and at the same time strengthen the ability of language expression. 
Table 1 The result of the questionnaire survey [N=182]

\begin{tabular}{|c|c|c|c|c|c|c|}
\hline \multirow[b]{2}{*}{ Investigation project } & \multicolumn{2}{|c|}{ Remarkable effect } & \multicolumn{2}{|c|}{ General effect } & \multicolumn{2}{|c|}{ No obvious effect } \\
\hline & $\begin{array}{c}\text { Numbe } \\
\mathbf{r}\end{array}$ & Percentage & Number & Percentage & Number & Percentage \\
\hline $\begin{array}{l}\text { The ability to master theoretical } \\
\text { knowledge }\end{array}$ & 172 & 94.5 & 6 & 3.3 & 4 & 2.2 \\
\hline Ability to think independently & 175 & 96.2 & 5 & 2.7 & 2 & 1.1 \\
\hline Project R \& D capacity & 176 & 96.8 & 3 & 1.6 & 3 & 1.6 \\
\hline Team cooperation ability & 170 & 93.5 & 7 & 3.8 & 5 & 2.7 \\
\hline Language expressive ability & 173 & 95.1 & 5 & 2.7 & 4 & 2.2 \\
\hline Ability to consult literature & 172 & 94.6 & 7 & 3.8 & 3 & 1.6 \\
\hline
\end{tabular}

\section{Conclusions}

CBL teaching method based on network teaching platform has achieved good results in the teaching of JAVA program design, but some problems should be paid attention to in the application process. (1) Teachers should choose appropriate cases. In the early stage of teaching, relatively simple cases should be selected, mainly because the students have just come into contact with the JAVA language program design, and lack of too profound grammar knowledge and programming ability. Only by choosing the right cases can we help students learn knowledge and stimulate students' interest in learning. At the same time, when choosing cases, we should pay attention to the typical and enforceability of cases. The cases selected by teachers must be consistent with the knowledge points of the course professors, and the key points should be emphasized so as to help students transform knowledge into abilities. (2) Teachers should be good at mobilizing students' enthusiasm for learning. For example, in the preparation of cases, we should pay attention to the vivid image of the case, and set up some in - depth procedures to attract students to enter the situation, in order to stimulate students' interest in learning and enthusiasm, and to cultivate students' ability to think independently. (3) Keep step by step. In the early stage of teaching, students should choose relatively simple and easy to understand cases. The knowledge involved should be relatively simple, so as to avoid attacking students' learning enthusiasm. With the gradual improvement of students' knowledge and ability, teachers should choose a broader and more complicated case. In a word, in the process of teaching, teachers should step by step according to the actual situation of students, and gradually enhance their comprehensive ability and comprehensive quality.

To sum up, the case teaching method based on the network teaching platform in the JAVA program design classroom teaching, does help to enhance the initiative of the classroom teaching, can fully mobilize the enthusiasm of the students, and improve the students' practical ability and the ability to explore, cooperate and create new abilities; at the same time, it is beneficial to students to master the ability. Theoretical knowledge is a teaching mode worthy of popularization and application.

\section{References}

[1] Shi Ningzhong. Adhering to the people-oriented modern educational philosophy. Chinese Education Journal, 2010 (02): 96.

[2] Zhang Weiyuan. Theoretical construction and application of web-based instructional development mode. Modern distance education research, 2013 (01): 7-14+23.

[3] Huang Dequn. Application Research of blended learning mode based on university network teaching platform. Journal of distance education, 2013, 31 (03): 64-70.

[4] Wan Meng, Li Xiaohui. Case teaching method. Chinese university teaching, 2014 (03): 73-79.

[5] Leng Chuanli. Case teaching method in the context of Chinese legal education. Degree and graduate education, 2015 (04): 35-40. 
[6] Sun Si. On the application of case teaching method in JAVA teaching. Information and computer (theoretical version), 2016 (04): 246+248.

[7] Dong Wei, Wen Yanjun, Li Tun, Qi Zhichang. Reflections on the online course construction of software engineering. Computer education, 2015 (06): 51-55.

[8] Yin Ansheng, Yuan Zhou min. a process oriented evaluation model for teacher's teaching effect research. Heilongjiang higher education research.2016 (12): 67-71. 